\title{
Antigenic mimicry-mediated anti-prion effects induced by bacterial enzyme succinylarginine dihydrolase in mice
}

Daisuke Ishibashi ${ }^{\mathrm{a}}$, Hitoki Yamanaka ${ }^{\mathrm{a}}$, Tsuyoshi Mori ${ }^{\mathrm{b}}$, Naohiro Yamaguchi ${ }^{\mathrm{a}}$, Yoshitaka Yamaguchi $^{\mathrm{b}}$, Noriyuki Nishida ${ }^{\mathrm{a}}$ and Suehiro Sakaguchi ${ }^{\mathrm{b}, *}$

${ }^{\mathrm{a}}$ Department of Molecular Microbiology and Immunology, Nagasaki University Graduate School of Biomedical Sciences, 1-12-4 Sakamoto, Nagasaki 852-8523, Japan

${ }^{b}$ Division of Molecular Neurobiology, The Institute for Enzyme Research, The University of Tokushima, 3-18-15 Kuramoto-cho, Tokushima 770-8503, Japan

Running title: Antigenic mimicry-mediated prion vaccine

*Corresponding author at Division of Molecular Neurobiology, The Institute for Enzyme Research, The University of Tokushima, 3-18-15 Kuramoto-cho, Tokushima 770-8503, Japan Tel.: +81 88633 7438; Fax: +81 886337440 .

E-mail: sakaguch@ier.tokushima-u.ac.jp

Keywords: prion, vaccine, antigenic mimicry, humoral immunity 


\begin{abstract}
Prions, the causative agents of prion diseases, are immunologically tolerated because their major component, prion protein (PrP), is a host-encoded molecule. Therefore, no effective prion vaccines have been developed. We previously showed that heterologous bovine and sheep PrP immunizations of mice overcame tolerance by an antigenic mimicry mechanism to efficiently induce anti-PrP auto-antibodies (Abs), significantly prolonging incubation times in mice subsequently infected with the mouse-adapted Fukuoka-1 prion. These results prompted us to investigate if non-mammal derived molecules able to antigenically mimic anti-prion epitopes, could act as prion vaccines. We show here that immunization of mice with recombinant succinylarginine dihydrolase, a bacterial enzyme with a peptide sequence similar to an anti-prion epitope, induced anti-PrP auto-Abs with anti-prion activity and significantly retarded survival times of the mice subsequently infected with Fukuoka-1 prions. These results might open a way for development of a new type of antigenic mimicry-based prion vaccine.
\end{abstract}




\section{Introduction}

Prion diseases, which include Creutzfeldt-Jakob disease (CJD) in humans and bovine spongiform encephalopathy (BSE) and scrapie in animals, are neurodegenerative disorders caused by prions $[1,2]$. It is believed that BSE prions have been orally transmitted to humans via contaminated foods, causing a new variant type of CJD (vCJD) [3, 4]. Fortunately, BSE incidence has been dramatically decreased, mainly due to the ban on using meat and bone meal ingredients in animal feed, thereby reducing the risk of BSE transmission to humans. In contrast, 4 vCJD cases were reported among recipients transfused with blood from donors who eventually developed vCJD [5-7], suggesting an increasing risk of secondary transmission of vCJD among human populations via medical treatments and/or procedures. However, no prophylactic vaccines against prion diseases have been developed.

Prions are mainly composed of the proteinase K (PK)-resistant prion protein, designated $\mathrm{PrP}^{\mathrm{Sc}}$, which is produced by conformational conversion of the normal cellular isoform, $\operatorname{PrP}^{\mathrm{C}}$, a glycosylphosphatidylinositol-anchored membrane glycoprotein abundantly expressed in neurons $[1,2]$. Thus, PrP is a potential candidate molecule for prion vaccines. Indeed, mice transgenically expressing 6H4 anti-PrP monoclonal antibody (mAb) developed the disease with very prolonged onset after intraperitoneal infection with mouse-adapted scrapie RML prions [8]. Moreover, passive immunization with anti-PrP mAbs, ICSM 18 and 35, markedly attenuated the disease in mice intraperitoneally infected with RML prions [9]. However, PrP is a host-encoded protein. Therefore, PrP vaccines might cause autoimmune reactions in an immunized host. In addition, PrP vaccines have another possible adverse effect 
as immunized PrPs might be converted into infectious PrPs or prions. Indeed, it was recently reported that recombinant mouse PrP (rMoPrP) mixed with RNAs and lipids, both of which are ubiquitous molecules in vivo, was converted into infectious $\mathrm{PrP}$ or a prion in vitro after being subjected to protein misfolding cyclic amplification (PMCA) [10]. These indicate that, molecules other than PrP, may be useful as prion vaccines.

We previously demonstrated that heterologous PrPs function as antigen mimicking molecules to host PrP [11]. Heterologous recombinant bovine and sheep PrPs were highly immunogenic in mice, efficiently inducing anti-PrP auto-Abs, and immunization with these proteins significantly prolonged incubation times in mice inoculated with the mouse-adapted Fukuoka-1 prion [11]. This therefore suggested that certain molecules, if able to antigenically mimic anti-prion epitopes, could behave as prion vaccines.

The aim of this study is to investigate this possibility. We show here that immunization of mice with recombinant succinylarginine dihydrolase (SADH), a bacterial molecule with a sequence similar to the $6 \mathrm{H} 4$ anti-prion epitope, elicited Abs not only to itself but also crossreactive Abs to the $6 \mathrm{H} 4$ epitope of PrP. We also show that the anti-SADH sera possessed anti-prion activity, reducing $\operatorname{PrP}^{\mathrm{Sc}}$ levels in prion-infected cells, and that immunization of the recombinant protein significantly retarded survival times of mice infected with Fukuoka-1 prions. These results suggest that antigenic mimicry-based prion vaccines might be considered as a new type of prion vaccine to be studied. 


\section{Materials and methods}

\subsection{Animals}

4-week old female BALB/c mice were purchased from SLC Japan, Shizuoka, Japan. Mice were cared for in accordance with the Guidelines for Animal Experimentation of Nagasaki University.

\subsection{Expression and purification of recombinant proteins}

A DNA fragment corresponding to residues 297-447 of SADH (GenBank accession No. U00096) of DH5 $\alpha$ Escherichia coli was amplified by polymerase chain reaction (PCR) using a sense primer (3'-ccggatccgtatggggttatctcaatga-5'; underlined sequence, BamH I site) and an anti-sense primer (3'-gggtcgactccattgcccctccetcgeg-5'; underlined sequence, Sal I site). A DNA fragment encoding residues 331-447 of SADH of Salmonella enterica subspecies enterica serovar Paratyphi A str. ATCC 9150 (GenBank accession No. NC006511) was also amplified by PCR using a sense primer (3'-cggatcctcagatgctgtggegecta-5'; underlined sequence, BamH I site) and an anti-sense primer (3'-gggtcgactccatcagccgecccegttgct-5'; underlined sequence, Sal I site). Following sequence confirmation of the PCR products, the fragments were digested with BamH I and Sal I and inserted into a pQE30 vector (QIAGEN, Hilden, Germany) and the vector developed to produce the protein of interest with an N-terminal $6 \times$ His tag. E.coli(M15) cells were freshly transformed by the plasmids, cultured in LB medium containing $1 \mathrm{mM}$ isopropylthio- $\beta$-D-galactoside (IPTG), and collected by centrifugation. The collected cells were lysed using CelLytic B Bacterial Cell Lysis/Extraction 
Reagent (Sigma-Aldrich Co. St Louis, USA) in the presence of deoxyribonuclease I and the lysate was centrifuged at $25,000 \times \mathrm{g}$ for $10 \mathrm{~min}$. The resulting pellet containing SADH protein was suspended in Reagent containing $0.2 \mathrm{mg} / \mathrm{ml}$ lysozyme and incubated with occasional shaking at room temperature (RT) for $15 \mathrm{~min}$. Volume of the suspension was then increased by addition of 1:10 diluted Reagent and centrifuged at $25,000 \times \mathrm{g}$ for $10 \mathrm{~min}$. The resulting pellet was washed 3 times with 1:10 diluted Reagent, suspended in lysis buffer (8 M Urea, 10 $\mathrm{mM}$ Tris- $\mathrm{HCl}, 100 \mathrm{mM} \mathrm{Na}_{2} \mathrm{HPO}_{4}, \mathrm{pH}$ 8.0) and SADH recombinant proteins were purified using a Ni-NTA column in denaturing conditions as recommended in the manufacturer's protocol.

Recombinant mouse PrP (rMoPrP) without a $6 \times$ His tag was expressed and purified as described elsewhere [11]. In brief, a DNA fragment corresponding to MoPrP 23-231 was amplified by PCR. Following sequence confirmation, this fragment was digested with Nde I and BamH I and inserted into a pET11a vector (Novagen, Inc., WI, USA). E. coli (BL21) cells were transformed and cultured in LB medium. $\mathrm{rMoPrP}$ was purified by subjecting the extract of the cells into a CM-sepharose column (Amersham Pharmacia Biotech AB, Uppsala, Sweden).

\subsection{Immunization}

Purified recombinant proteins were dialyzed against PBS. $100 \mu \mathrm{g}$ of the dialyzed protein was intraperitoneally inoculated into a 4-week old female BALB/c mouse (SLC Japan) together with complete Freund's adjuvant (CFA; Difco Laboratories, Detroit, MI) for the first 
immunization. Additional immunizations were performed by intraperitoneal inoculation of the same amounts of the protein with incomplete Freund's adjuvant (Difco Laboratories) into the mice at 2-week intervals. Antisera were collected one week after the final immunization and stored at $-20^{\circ} \mathrm{C}$ until used.

\subsection{Enzyme-linked immunosorbent assay (ELISA)}

For detection of purified SADH recombinant proteins or $\mathrm{rMoPrP}$ without a $6 \times \mathrm{His}$ tag, each well of a 96 well immunoplate (Nunc, Roskilde, Denmark) was coated with $500 \mathrm{ng}$ of the proteins by overnight incubation at $4{ }^{\circ} \mathrm{C}$ and then blocked with $\mathrm{PBS}$ containing $0.05 \%$ Tween-20 (T-PBS) and 25\% Blocking One (Nakarai tesque Co., Kyoto, Japan) at $37^{\circ} \mathrm{C}$ for 1 hr. To detect specific IgG Abs, serially 10-fold diluted antiserum was added to the wells for 1 hr at $37^{\circ} \mathrm{C}$ and unbound Abs were removed by washing twice with T-PBS. Immune complexes were detected using secondary goat anti-mouse IgG Abs conjugated with HRP (GE Healthcare, $\quad$ Buckinghamshire, $\quad$ England), $\quad 2 \quad \mathrm{mM}$ 2,2'-Azino-bis(3-Ethylbenzthiazoline-6-sulfonic acid), and $0.04 \% \mathrm{H}_{2} \mathrm{O}_{2}$. Antibody titers were determined using colorimetric values expressed at $405 \mathrm{~nm}$.

For detection of a MoPrP peptide 131-154 (>70\% purity, Sigma-Aldrich Japan K. K., Hokkaido, Japan), we used a more sensitive ELISA system. $1 \mu \mathrm{g}$ of the peptide was coated on a 96 well immunoplate (Nunc) and similarly subjected to the procedures described above except that the immunocomplexes were detected using 3,3',5,5'-tetramentylbenzidine (Pierce, Rockford, IL) at $450 \mathrm{~nm}$. 


\subsection{Fluorescence-activated cell sorter (FACS) analysis}

$\mathrm{PrP}^{\mathrm{C}}$-deficient hippocampal neurons, designated HpL3-4 [12], and HpL3-4 cells overexpressing exogenous $\operatorname{PrP}^{\mathrm{C}}$, designated HpL3-4TR [12] (kindly provided by Prof. Onodera, The University of Tokyo, Japan), were harvested in PBS containing 20 mM EDTA. Cells were then suspended in BSS buffer $\left(140 \mathrm{mM} \mathrm{NaCl}, 5.4 \mathrm{mM} \mathrm{KCl}, 0.8 \mathrm{mM} \mathrm{MgSO}_{4}, 0.3\right.$ $\mathrm{mM} \mathrm{Na}_{2} \mathrm{HPO}_{4}, 0.4 \mathrm{mM} \mathrm{KH}_{2} \mathrm{PO}_{4}, 1 \mathrm{mM} \mathrm{CaCl}$ ) containing 5\% fetal bovine serum (FBS), and incubated with 100 -fold diluted antisera for $1 \mathrm{hr}$ on ice. The treated cells were then washed 3 times with BSS buffer containing 5\% FBS, reacted with Alexa Fluor ${ }^{\circledR} 546$ goat anti-mouse IgG (Invitrogen, Carlsbad, CA) and analyzed using a flow cytometer (BD FACSCanto ${ }^{\mathrm{TM}}$ II Flow Cytometer, BD Biosciences, San Jose, CA).

\subsection{Western blotting analysis}

Total proteins of cell lysates treated with or without $20 \mu \mathrm{g} / \mathrm{ml}$ of proteinase $\mathrm{K}$ (PK) (Sigma-Aldrich Co.) at $37^{\circ} \mathrm{C}$ for $30 \mathrm{~min}$ were separated on $15 \%$ SDS-PAGE and electrically transferred onto a PVDF membrane (Millipore, MA, USA). The PK activity was blocked by boiling in a buffer (50 mM Tris-HCl, $\mathrm{pH}$ 6.8, 5\% glycerol, 1.6\% SDS, $100 \mathrm{mM}$ dithiothreitol) for $5 \mathrm{~min}$. The membrane was immersed in TBST $(0.1 \%$ Tween $20,100 \mathrm{mM} \mathrm{NaCl}, 10 \mathrm{mM}$ Tris-HCl, $\mathrm{pH}$ 7.6) containing 5\% nonfat dry milk and then incubated either with 1:5000-diluted M-20 anti-PrP goat polyclonal Ab (Santa Cruz Biotechnology, Inc., Santa Cruz, $\mathrm{CA}$ ) to detect $\mathrm{PrP}$ or with 1:5000-diluted $\mathrm{Ab}$ against $\beta$-actin (Sigma-Aldrich Co.). Immune 
complexes were visualized using secondary sheep anti-mouse IgG Abs conjugated with HRP (GE Healthcare) and the ECL system (GE Healthcare).

\subsection{In vitro assay of anti-prion activity of anti-sera}

The in vitro anti-prion activity of antisera was assessed by their activities to reduce $\operatorname{PrP}^{\mathrm{Sc}}$ levels in mouse neuroblastoma N2a cell line persistently infected with a mouse-adapted Fukuoka-1 prion, termed N2a58-Fk [13]. The cells were cultured in DMEM containing 10\% FBS. $2 \times 10^{5}$ cells in one well of a 6 well plate were incubated with 1:10 or 1:50-diluted antisera for 2 days. The cells were then lysed in a lysis buffer ( $1 \%$ TritonX-100, 1\% sodium deoxycholate, $300 \mathrm{mM} \mathrm{NaCl}, 100 \mathrm{mM}$ Tris-HCl, $\mathrm{pH}$ 7.5) and the lysates were subjected to Western blotting.

\subsection{Prion inoculation}

Brains were removed from diseased mice infected with the mouse-adapted Fukuoka-1 prion [14] and then homogenized to $1 \%(\mathrm{w} / \mathrm{v})$ in PBS. Aliquots $(100 \mu \mathrm{l})$ of the homogenate were intraperitoneally inoculated into each mouse 1 week after receiving 5 immunizations.

\subsection{Cell viability assay}

Cell viability was determined by usingthe PreMix WST-1 Cell Proliferation Assay System (Takara Bio Inc., Shiga, Japan). N2a58 cells were plated on 96-well plates at a density of $5 \times$ $10^{3}$ cells/well in $100 \mu \mathrm{l}$ of Dulbecco's Modified Eagle Medium (DMEM) containing 10\% 
FBS. On the next day, each of the antisera was added into the culture medium at the final concentration of $10 \%$. After $48 \mathrm{hr}$, the WST-1 assay was performed according to the manufacturer's instructions. In brief, the cells treated with antisera were incubated with PreMix WST- 1 substances for $3 \mathrm{hr}$ at $37^{\circ} \mathrm{C}$, and then their absorbance was measured at 450 nm.

\subsection{Histology}

The brain tissues of mice were fixed in 4\% paraformaldehyde and sectioned into 5- $\mu$ m-thick sections after paraffin embedding. The tissue sections were stained with hematoxylin and $\operatorname{eosin}(\mathrm{HE})$.

\subsection{Statistical analysis}

Logrank test was used for analysis of the survival times of mice. Colorimetric data from ELISA were subjected to one way ANOVA followed by Tukey-Kramer multiple comparison testing.

\section{Results}

\subsection{Bacterial enzyme SADH has an amino acid sequence similar to $6 \mathrm{H} 4$ anti-prion epitope}

We selected the $6 \mathrm{H} 4$ anti-prion epitope, which corresponds to residues 144-152 of MoPrP

[15] (Fig. 1A), as a target sequence because this epitope overlaps the ICSN18 anti-prion 
epitope (residues 146-159) [9], and both 6H4 and ICSN18 mAbs have already been demonstrated to be effective against prions in mice [8, 9]. We then searched for non-mammal-derived molecules with sequences similar to the epitope using Basic Local Alignment Search Tool in the National Center for Biotechnology Information website (http://blast.ncbi.nlm.nih.gov/Blast.cgi). As a result, we found a 6H4-mimicking sequence in the bacterial enzyme SADH (Fig. 1A). SADH is a much conserved molecule involved in the arginine succinyltransferase pathway in Escherichia coli and related bacteria including Salmonella enterica subspecies, Klebsiella aerogenes and Pseudomonas aeruginosa [16].

\subsection{SADHs elicit marked Ab responses in mice}

To investigate whether or not SADH proteins could be immunogenic in mice, we first recombinantly expressed and purified the recombinant SADH protein from Escherichia coli [hereafter referred to as $\mathrm{SADH}(E)]$ or Salmonella enterica subspecies enterica serovar Paratyphi A strain [hereafter referred to as $\operatorname{SADH}(S)$ ] (Fig. 1B). The recombinant proteins were designed to have the mimicking sequence at the center and a $6 x$ His sequence at the N-terminus. The $\operatorname{SADH}(S)$ recombinant protein was higher than $\operatorname{SADH}(E)$ in molecular weight because of an additional 35 amino acids in the N-terminal region. The purified recombinant proteins were then intraperitoneally inoculated into BALB/c mice 5 times at 2-week intervals. We collected antisera from the mice 1 week after the final immunization and subjected them to an ELISA to detect specific IgG responses against the respective immunogens. No increase in optical density values at $405 \mathrm{~nm}\left(\mathrm{OD}_{405}\right)$ was observed against 
$\operatorname{SADH}(E)$ and $\operatorname{SADH}(S)$ immunogens with control sera from non-immunized mice (Fig. 1C). In contrast, anti-SADH $(E)$ and anti-SADH $(S)$ sera from each of the immunized mice showed very high $\mathrm{OD}_{405}$ values against the respective immunogens (Fig. 1C). These results indicate that $\mathrm{SADH}(E)$ and $\mathrm{SADH}(S)$ recombinant proteins are highly immunogenic in mice, inducing very high $\mathrm{Ab}$ responses.

\subsection{SADHs induce anti-PrP auto-Abs in mice}

We then investigated whether or not SADH proteins could induce anti-PrP auto-Abs in mice. Since the immunizing recombinant proteins contained a 6xHis tag, we used untagged rMoPrP as an ELISA antigen to eliminate reactivity against the tag with crossreacting Abs that might be produced in the immunized mice. Compared to non-immunized sera, significantly higher $\mathrm{OD}_{405}$ values were detected with anti-SADH$(E)$ and anti-SADH $(S)$ sera (Fig. 2A). These results indicate that immunization with SADHs could induce anti-PrP auto-Abs in mice. We also investigated whether the antisera could recognize native $\operatorname{PrP}$ or $\operatorname{PrP}^{\mathrm{C}}$ expressed on the cell surface using FACS analysis. HpL3-4 cells are devoid of $\operatorname{PrP}^{\mathrm{C}}$ while HpL3-4TR cells express abundant $\operatorname{PrP}^{\mathrm{C}}$ on their surface. Non-immunized sera induced no signal shift of HpL3-4TR cells, compared to the signal of HpL3-4 cells (Fig. 2B, left panel). In contrast, the signal of HpL3-4TR cells was slightly but distinctly shifted to the right by the anti-SADH $(S)$ (Fig. 2B, middle panel) and anti-SADH(E) sera(Fig. 2B, right panel), indicating that the anti-SADH sera recognize $\operatorname{PrP}^{\mathrm{C}}$ expressed on the cell surface. 


\subsection{Anti-SADH sera recognize the $6 \mathrm{H} 4$ anti-prion epitope}

$\operatorname{SADH}(E)$ and $\operatorname{SADH}(S)$ recombinant proteins have an amino acid sequence similar to the $6 \mathrm{H} 4$ anti-prion epitope. We therefore investigated if anti-SADH $(E)$ and anti-SADH $(S)$ sera could react with the epitope using an ELISA with a PrP peptide 131-154, which encompasses the $6 \mathrm{H} 4$ epitope. We used a more sensitive ELISA for detecting the peptide because the conventional ELISA used for detection of full-length rMoPrP was less sensitive to detecting the specific signals of the peptide [11]. This sensitive ELISA resulted in higher backgrounds from non-immunized sera (Fig. 2C). However, the 20-fold diluted anti-SADH $(E$ ) and anti-SADH $(S)$ sera showed significantly higher $\mathrm{OD}_{450}$ values, compared to control non-immunized sera (Fig. 2C), indicating that $\operatorname{SADH}(E)$ and $\operatorname{SADH}(S)$ recombinant proteins induce anti-PrP auto-Abs reacting with the $6 \mathrm{H} 4$ anti-prion epitope in mice.

\subsection{Anti-SADH sera decrease PrP $P^{S c}$ levels in a prion-infected cell line}

We also investigated if anti-SADH sera could have anti-prion activities. Mouse neuroblastoma N2a cell line persistently infected with Fukuoka-1 prions, termed N2a58-Fk, was incubated for 2 days with 10 or 50 -fold diluted anti-sera and thereafter subjected to Western blotting with M-20 anti-PrP $\mathrm{Ab}$, which recognizes the C-terminal part of $\operatorname{PrP}$. $\operatorname{Anti-SADH}(E)$ or anti-SADH $(S)$ sera taken from two immunized mice reduced $\mathrm{PrP}^{\mathrm{Sc}}$ levels in the cells in a dose-dependent manner, compared to the $\mathrm{PrP}^{\mathrm{Sc}}$ levels in the cells treated with non-immunized sera (Fig. 3A). Total PrP levels in N2a58-Fk and $\operatorname{PrP}^{\mathrm{C}}$ levels in uninfected parental N2a58 cells were not affected by the treatment with these antisera (Fig. 3A and B). 
No cytotoxicity was detected with these antisera in N2a58 cells (Fig. 3C). These results indicate that immunization with $\operatorname{SADH}(E)$ and $\operatorname{SADH}(S)$ recombinant proteins induce anti-prion $\mathrm{Abs}$ in mice, and that anti-SADH$(E)$ or anti-SADH$(S)$ sera are effective against prions in $\mathrm{N} 2 \mathrm{a} 58$-Fk cells without affecting the $\mathrm{PrP}^{\mathrm{C}}$ levels.

\subsection{Effects of immunization with $\mathrm{SADH}$ recombinant proteins against mouse-adapted prion in mice}

We investigated the effects of the immunization with SADH recombinant proteins against prions. BALB/c mice were intraperitoneally immunized with purified recombinant $\operatorname{SADH}(E)$ and $\operatorname{SADH}(S)$ proteins 5 times at 2-week intervals and thereafter intraperitoneally inoculated with Fukuoka-1 prion 1 week after the final immunization. Non-immunized mice eventually died of the disease $298 \pm 28$ days post-inoculation (p.i.) (Table 1). However, mice immunized with $\operatorname{SADH}(E)$ and $\operatorname{SADH}(S)$ recombinant proteins displayed significantly longer survival times at $329 \pm 15(p=0.0284)$ and $321 \pm 21$ days p.i. $(p=0.0384)$, respectively (Table 1$)$. HE staining of the brains of terminally ill mice either immunized with the recombinant proteins or non-immunized revealed indistinguishably abundant vacuoles throughout the brains, particularly in the cortex, the thalamus and the cerebellar white matter (Fig.4). Hippocampal neurons seemed undamaged in the immunized mice, compared to those in non-immunized control mice (Fig. 4). No lymphocyte infiltration was detected in the brains of the immunized and non-immunized mice by immunohistochemistry using anti-T cell Abs, including anti-CD4 and anti-CD8 Abs, and an anti-B cell Ab, such as anti-CD45R Ab (data not shown). 
These results indicate that immunization with $\operatorname{SADH}(E)$ and $\operatorname{SADH}(S)$ recombinant proteins are effective against prion infection in mice without affecting the final pathology in the brain.

\section{Discussion}

In the present study, we showed that the bacterial enzymes $\operatorname{SADH}(E)$ and $\operatorname{SADH}(S)$, which carry a peptide sequence mimicking the $6 \mathrm{H} 4$ anti-prion epitope, are highly immunogenic in mice, eliciting $\mathrm{Ab}$ responses against not only themselves but also the $6 \mathrm{H} 4$ epitope. We also showed that anti-SADH $(E)$ and anti-SADH $(S)$ sera were able to prevent $\operatorname{PrP}^{\mathrm{Sc}}$ formation in N2a cells that were persistently infected with Fukuoka-1 prion, and that immunization with the recombinant proteins significantly prolonged survival times in mice subsequently infected with Fukuoka-1 prion. These results indicate that the $6 \mathrm{H} 4$ mimicking sequence in $\mathrm{SADH}(E)$ and $\operatorname{SADH}(S)$ recombinant proteins was immunogenic in mice, eliciting anti-prion Abs that recognize the $6 \mathrm{H} 4$ epitope and thereby exerting anti-prion activities.

We previously showed that immunization of CFA with $\mathrm{rMoPrP}$ into BALB/c mice with the same regimen as we employed in this study had no effects on the survival times of the mice intraperitoneally infected with Fukuoka-1 prion [11]. In contrast, the same immunization using CFA with heterologous bovine or sheep rPrP significantly extended the survival times of the immunized mice [11]. $\mathrm{rMoPrP}$ was immunologically tolerated in $\mathrm{BALB} / \mathrm{c}$ mice while bovine and sheep rPrPs were highly immunogenic in BALB/c mice, inducing anti-PrP auto-Abs [11]. These results clearly indicate that the anti-prion effects in 
BALB/c mice immunized with $\operatorname{SADH}(E)$ and $\operatorname{SADH}(S)$ recombinant proteins are due to the immunization of the recombinant proteins, not due to the CFA.

The exact mechanism for the protective effects of the immunization with $\operatorname{SADH}(E)$ and $\operatorname{SADH}(S)$ recombinant proteins against the prion infection remains unknown. The peripherally inoculated prions first accumulate in the peripheral lymphoreticular tissues, such as spleen and lymph nodes, before invading the central nervous system. White et al. showed that passive immunization of anti-PrP mAbs, ICSM 18 and 35, into the peritoneal cavity markedly reduced accumulation of $\operatorname{PrP}^{\mathrm{Sc}}$ and infectivity in the spleen of mice intraperitoneally infected with RML prions and attenuated the disease in these mice [9]. However, the same administration of these mAbs showed no effect on the disease in the mice already developing clinical symptoms or intracerebrally infected with the prions [9]. This is probably because Abs are unable to efficiently infiltrate the brain across the blood-brain barrier. These results indicate that substantial suppression of peripheral prion replication early in the incubation period could be protective against prion diseases. However, at present, we do not know whether immunization with $\operatorname{SADH}(E)$ and $\operatorname{SADH}(S)$ recombinant proteins would be effective against the peripheral prion replication.

Significantly higher $\mathrm{OD}_{450}$ values were obtained by ELISA with anti-SADH sera against peptide 131-154, which encompasses the $6 \mathrm{H} 4$ epitope, clearly indicating that the immunization with $\operatorname{SADH}(E)$ and $\operatorname{SADH}(S)$ recombinant proteins elicited Abs reactive with the $6 \mathrm{H} 4$ epitope in mice. Instead of the conventional ELISA used for detection of full-length rMoPrP, we used a more sensitive ELISA for detecting peptide 131-154. This is because we 
anti-SADH $(E)(\mathrm{n}=2)$ and anti-SADH $(S)$ sera $(\mathrm{n}=2)$ and then subjected to a cell viability assay. No significant reduction in the cell viability was detected in these cells.

Fig. 4. HE staining of the brains of terminally ill mice with or without SADH recombinant protein immunization. No disease-specific vacuoles were observed in the brains of uninfected mice. In contrast, terminally ill mice either immunized with the recombinant proteins or not, exhibited many vacuoles indistinguishably over their brains. 
PrP vaccines may risk causing adverse effects in the immunized host. First, it was shown that certain anti-PrP mAbs against residues 95-105 or the octapeptide repeat region were neurotoxic in mice, causing neuronal cell death $[21,22]$. Thus, $\operatorname{PrP}$ vaccines might induce such neurotoxic anti-PrP Abs in the immunized host. Second, since PrP is a host protein, PrP vaccines might cause autoimmune responses in the immunized host. Third, importantly, it was reported that $\mathrm{rMoPrP}$ was converted into infectious $\operatorname{PrP}$ in vitro by incubating with ubiquitous molecules, RNAs and lipids, and being subjected to PMCA [10]. Thus, PrP vaccines might have the possibility that immunizing PrP molecules are converted into infectious PrPs or prions in the immunized host. Considering these potential risks, $\operatorname{PrP}$ vaccines might be unfavorable as prion vaccines.

$\operatorname{SADH}(E)$ and $\operatorname{SADH}(S)$ contain a sequence mimicking the $6 \mathrm{H} 4$ epitope, but their overall amino acid sequences are quite different from PrPs. Therefore, unlike PrPs, $\operatorname{SADH}(E)$ and $\operatorname{SADH}(S)$ have no potential to be converted into an infectious molecule. No autoimmune responses were also reported in mice transgenically expressing $6 \mathrm{H} 4 \mathrm{mAb}$ [15]. $\mathrm{PrP}^{\mathrm{C}}$ is most abundantly expressed in the brain. However, we detected no lymphocyte infiltration in the brains of terminally ill mice immunized with the recombinant proteins on immunohistochemical analysis. Moreover, no neurotoxic effects were shown with $6 \mathrm{H} 4 \mathrm{mAb}$ in mice [15]. Indeed, on inspection, we did not detect any abnormal behaviors in mice immunized with $\operatorname{SADH}(E)$ and $\operatorname{SADH}(S)$ recombinant proteins, compared to non-immunized mice. Hippocampal neurons were shown to be very vulnerable to the toxicity of $4 \mathrm{H} 11$ anti-PrP antibody in mice $[21,22]$. However, we observed no significant loss of hippocampal 
neurons in terminally ill mice immunized with $\operatorname{SADH}(E)$ and $\operatorname{SADH}(S)$ recombinant proteins. Taken together, these indicate that $\operatorname{SADH}(E)$ and $\operatorname{SADH}(S)$ recombinant proteins as antigens lack the adverse effects that might be potentially induced by PrP vaccines. Therefore, our present results suggest that, rather than $\operatorname{PrP}$ molecules, $\operatorname{SADH}(E)$ and $\operatorname{SADH}(S)$ or other non-mammal derived molecules carrying an amino acid sequence(s) antigenically mimicking the anti-prion epitopes could be candidate molecules for study as prion vaccines.

However, immunization with $\operatorname{SADH}(E)$ and $\operatorname{SADH}(S)$ recombinant proteins displayed significant but slight effects against Fukuoka-1 prions in mice. The increase in incubation times for the disease closely correlates with the titers of anti-PrP auto-Abs produced in immunized mice $[17,23]$. Sigurdsson et al. showed that mice producing higher titers of anti-PrP auto-Abs in plasma after subcutaneous immunization with mouse recombinant $\operatorname{PrP}$ developed the disease with longer incubation times after intraperitoneal infection with 139A prions. It was also reported that the protective effects of oral immunization with a mouse PrP-expressing attenuated Salmonella typhimurium LVR01 LPS vaccine strain against oral prion infection were nicely correlated to the titers of anti-PrP IgG and IgA auto-Abs produced in the immunized mice [23]. It is thus suggested that the modest effects of the immunization with $\operatorname{SADH}(E)$ and $\operatorname{SADH}(S)$ recombinant proteins against Fukuoka-1 prions might be attributable to low titers of the anti-PrP auto-Abs produced in the immunized mice. Indeed, anti-SADH $(E)$ and anti-SADH $(S)$ sera showed very low $\mathrm{OD}_{405}$ values against $\mathrm{rMoPrP}$ on the ELISA, compared to those against recombinant $\operatorname{SADH}(E)$ and $\operatorname{SADH}(S)$ proteins. Thus, further studies are required to enhance the antigenicity of the mimic 
sequence in $\operatorname{SADH}(E)$ and $\operatorname{SADH}(S)$ recombinant protein to induce much higher titers of anti-prion Abs, enough to effectively prevent prion infection. Furthermore, it might be interesting to search for other non-mammalian molecules carrying an anti-prion epitope-mimic sequence(s) with higher antigenic properties. SADH is a very conserved molecule in Escherichia coli, Salmonella enterica subspecies, Klebsiella aerogenes and Pseudomonas aeruginosa [16]. Therefore, it might be of interest to investigate whether or not individuals exposed to these pathogens might carry anti-prion Abs.

\section{Conclusion}

We show here that immunization with the bacterial molecules $\operatorname{SADH}(E)$ and $\operatorname{SADH}(S)$, which carry a sequence similar to the $6 \mathrm{H} 4$ anti-prion epitope, elicited anti-prion $\mathrm{Abs}$ in mice and significantly retarded survival times of the mice infected with Fukuoka-1 prions. This indicates that antigenic mimicry-based prion vaccines might be a new type of prion vaccine worth studying.

\section{Acknowledgments}

We thank Ryuichiro Atarashi, Katsuya Satoh, Takehiro Nakagaki, Takayuki Fuse, Takehiro Matsubara, Kazunori Sano, for helpful discussions, and Mari Kudo for technical assistance. This work was supported in part by the global COE Program (F12); a Grant-in-Aid for Young 
Scientists (B) (No. 22790955) from the Ministry of Education, Culture, Sports, Science, and Technology of Japan; a grant for BSE research, and a grant-in-aid of the Research Committee of Prion disease and Slow Virus Infection, from the Ministry of Health, Labor and Welfare of Japan.

\section{References}

[1] Prusiner SB. Prions. Proc Natl Acad Sci U S A 1998;95(23):13363-83.

[2] Weissmann C, Enari M, Klohn PC, Rossi D, Flechsig E. Molecular biology of prions. Acta neurobiologiae experimentalis 2002;62(3):153-66.

[3] Hill AF, Desbruslais M, Joiner S, Sidle KC, Gowland I, Collinge J, et al. The same prion strain causes vCJD and BSE. Nature 1997;389(6650):448-50.

[4] Bruce ME, Will RG, Ironside JW, McConnell I, Drummond D, Suttie A, et al. Transmissions to mice indicate that 'new variant' CJD is caused by the BSE agent. Nature 1997;389(6650):498-501.

[5] Llewelyn CA, Hewitt PE, Knight RS, Amar K, Cousens S, Mackenzie J, et al. Possible transmission of variant Creutzfeldt-Jakob disease by blood transfusion. Lancet 2004;363(9407):417-21.

[6] Peden AH, Head MW, Ritchie DL, Bell JE, Ironside JW. Preclinical vCJD after blood transfusion in a PRNP codon 129 heterozygous patient. Lancet 2004;364(9433):527-9. 
[7] Zou S, Fang CT, Schonberger LB. Transfusion transmission of human prion diseases. Transfusion medicine reviews 2008;22(1):58-69.

[8] Heppner FL, Musahl C, Arrighi I, Klein MA, Rulicke T, Oesch B, et al. Prevention of scrapie pathogenesis by transgenic expression of anti-prion protein antibodies. Science $2001 ; 294(5540): 178-82$.

[9] White AR, Enever P, Tayebi M, Mushens R, Linehan J, Brandner S, et al. Monoclonal antibodies inhibit prion replication and delay the development of prion disease. Nature 2003;422(6927):80-3.

[10] Wang F, Wang X, Yuan CG, Ma J. Generating a prion with bacterially expressed recombinant prion protein. Science 2010;327(5969):1132-5.

[11] Ishibashi D, Yamanaka H, Yamaguchi N, Yoshikawa D, Nakamura R, Okimura N, et al. Immunization with recombinant bovine but not mouse prion protein delays the onset of disease in mice inoculated with a mouse-adapted prion. Vaccine 2007;25(6):985-92.

[12] Kuwahara C, Takeuchi AM, Nishimura T, Haraguchi K, Kubosaki A, Matsumoto Y, et al. Prions prevent neuronal cell-line death. Nature 1999;400(6741):225-6.

[13] Nishida N, Katamine S, Manuelidis L. Reciprocal interference between specific CJD and scrapie agents in neural cell cultures. Science 2005;310(5747):493-6.

[14] Tateishi J, Ohta M, Koga M, Sato Y, Kuroiwa Y. Transmission of chronic spongiform encephalopathy with kuru plaques from humans to small rodents. Annals of neurology 1979;5(6):581-4. 
[15] Korth C, Stierli B, Streit P, Moser M, Schaller O, Fischer R, et al. Prion (PrPSc)-specific epitope defined by a monoclonal antibody. Nature 1997;390(6655):74-7.

[16] Cunin R, Glansdorff N, Pierard A, Stalon V. Biosynthesis and metabolism of arginine in bacteria. Microbiological reviews 1986;50(3):314-52.

[17] Sigurdsson EM, Brown DR, Daniels M, Kascsak RJ, Kascsak R, Carp R, et al. Immunization delays the onset of prion disease in mice. Am $\mathrm{J}$ Pathol 2002;161(1):13-7.

[18] Polymenidou M, Heppner FL, Pellicioli EC, Urich E, Miele G, Braun N, et al. Humoral immune response to native eukaryotic prion protein correlates with anti-prion protection. Proc Natl Acad Sci U S A 2004;101 Suppl 2:14670-6.

[19] Yamanaka H, Ishibashi D, Yamaguchi N, Yoshikawa D, Nakamura R, Okimura N, et al. Enhanced mucosal immunogenicity of prion protein following fusion with B subunit of Escherichia coli heat-labile enterotoxin. Vaccine 2006;24(15):2815-23.

[20] Koller MF, Grau T, Christen P. Induction of antibodies against murine full-length prion protein in wild-type mice. Journal of neuroimmunology 2002;132(1-2):113-6.

[21] Solforosi L, Criado JR, McGavern DB, Wirz S, Sanchez-Alavez M, Sugama S, et al. Cross-linking cellular prion protein triggers neuronal apoptosis in vivo. Science 2004;303(5663):1514-6.

[22] Lefebvre-Roque M, Kremmer E, Gilch S, Zou WQ, Feraudet C, Gilles CM, et al. Toxic effects of intracerebral PrP antibody administration during the course of BSE 
infection in mice. Prion 2007;1(3):198-206.

[23] Goni F, Prelli F, Schreiber F, Scholtzova H, Chung E, Kascsak R, et al. High titers of mucosal and systemic anti-PrP antibodies abrogate oral prion infection in mucosal-vaccinated mice. Neuroscience 2008;153(3):679-86. 


\section{Figure Legends}

Fig. 1. High immunogenicity of the bacterial enzyme SADHs carrying a sequence mimicking the $6 \mathrm{H} 4$ anti-prion epitope in mice. (A) Comparison of the amino acid sequence of the $6 \mathrm{H} 4$ anti-prion epitope to the mimic sequences of $\operatorname{SADH}(E)$ and $\operatorname{SADH}(S)$. Arabic numbers represent the codon number of each indicated amino acid in each molecule. (B) Coomassie brilliant blue staining of purified $\operatorname{SADH}(E)$ and $\operatorname{SADH}(S)$ recombinant proteins. (C) The $\mathrm{OD}_{405}$ values of anti-SADH$(E)$ and anti-SADH $(S)$ sera against the respective antigens evaluated by an ELISA. Purified recombinant protein was intraperitoneally inoculated into BALB/c mice 5 times at 2-week intervals and anti-sera were taken 1 week after the final immunization. Compared to control sera from non-immunized mice $(\mathrm{n}=6)$, anti-SADH $(E)$ $(n=21)$ and anti-SADH $(S)$ sera $(n=20)$ showed very high $\mathrm{OD}_{405}$ values against the respective immunogens.

Fig. 2. SADH recombinant proteins induce anti-PrP auto-Abs able to recognize the $6 \mathrm{H} 4$ anti-prion epitope. (A) Anti-SADH(E) and anti-SADH $(S)$ sera recognize full-length $\mathrm{rMoPrP}$. $\operatorname{Anti-SADH}(E)(\mathrm{n}=10)$ and anti-SADH $(S)$ sera $(\mathrm{n}=9)$ were diluted 1:20 and subjected to an ELISA against purified $\mathrm{rMoPrP}$ without a $6 \mathrm{x}$ His tag. Higher $\mathrm{OD}_{405}$ values were detected with anti-SADH$(E)$ and anti-SADH $(S)$ sera than those of control sera $(\mathrm{n}=9)$ from non-immunized mice. (B) Anti-SADH $(E)$ and anti-SADH $(S)$ sera recognize $\operatorname{PrP}^{\mathrm{C}}$ on the cell surface. HpL3-4 and HpL3-4TR cells were subjected to FACS analysis with the antisera. $\operatorname{PrP} \mathrm{P}^{\mathrm{C}}$ 
on the HpL3-4TR cells was detected by the anti-SADH $(E)$ (middle panel) and anti-SADH $(S)$ sera (right panel) but not by non-immunized sera (left panel). (C) Anti-SADH(E) (n=16) and anti-SADH $(S)$ sera $(n=15)$ recognize the $6 \mathrm{H} 4$ anti-prion epitope. To investigate anti-SADH $(E)$ and anti-SADH $(S)$ sera for their binding activity to a $6 \mathrm{H} 4$ epitope-containing PrP peptide, we employed a more sensitive ELISA as described in Materials and Methods. $\operatorname{Anti-SADH}(E)$ and anti-SADH $(S)$ sera were diluted at 1:20 and subjected to the ELISA using the PrP peptide 131-154 encompassing the 6H4 epitope as an antigen. This sensitive ELISA resulted in higher backgrounds. However, significantly higher $\mathrm{OD}_{450}$ values were detected with anti-SADH $(E)$ and anti-SADH $(S)$ sera, compared to those with control non-immunized $\operatorname{sera}(\mathrm{n}=6) . * p<0.05 ; * * p<0.01$

Fig. 3. In vitro anti-prion activity of anti-SADH(E) and anti-SADH $(S)$ sera. (A) $\operatorname{Anti-SADH}(E)$ and anti-SADH $(S)$ sera reduce $\operatorname{PrP}^{\mathrm{Sc}}$ levels in prion-infected cells. N2a58-Fk cells were incubated for 2 days with anti-SADH$(E)(\mathrm{n}=2)$ and anti-SADH$(S)$ sera $(\mathrm{n}=2)$ at indicated dilutions and then subjected to Western blotting. Compared to non-immunized sera, anti-SADH $(E)$ or anti-SADH $(S)$ sera reduced $\operatorname{PrP}^{\mathrm{Sc}}$ levels in the cells in a dose-dependent manner without affecting the level of total PrP. (B) Anti-SADH $(E)$ and anti-SADH $(S)$ sera do not reduce $\operatorname{PrP}^{\mathrm{C}}$ levels in uninfected cells. N2a58 cells were similarly incubated with anti-SADH $(E)(\mathrm{n}=2)$ and anti-SADH$(S)$ sera $(\mathrm{n}=2)$. No significant reduction in the $\operatorname{PrP}^{\mathrm{C}}$ level was detected in these cells. (C) Anti-SADH(E) and anti-SADH $(S)$ sera are not cytotoxic. N2a58 cells were similarly incubated without $(-)$ or with non-immunized $(n=2)$, 
anti-SADH $(E)(\mathrm{n}=2)$ and anti-SADH $(S)$ sera $(\mathrm{n}=2)$ and then subjected to a cell viability assay. No significant reduction in the cell viability was detected in these cells.

Fig. 4. HE staining of the brains of terminally ill mice with or without SADH recombinant protein immunization. No disease-specific vacuoles were observed in the brains of uninfected mice. In contrast, terminally ill mice either immunized with the recombinant proteins or not, exhibited many vacuoles indistinguishably over their brains. 
Table 1. Prophylactic effects of immunization with SADHs on prion infection.

\begin{tabular}{|c|c|c|c|}
\hline Immunogen & $\begin{array}{c}\text { Survival times } \\
\text { (Mean } \pm \text { SD, days) }\end{array}$ & $\begin{array}{c}\text { No. of mice } \\
\text { (diseased/total) }\end{array}$ & $\begin{array}{c}p \text { values } \\
\text { (Logrank test) }\end{array}$ \\
\hline- & $298 \pm 28$ & $10 / 10$ & 0.0284 \\
\hline SADH $(E)$ & $329 \pm 15$ & $5 / 5$ & 0.0384 \\
\hline SADH $(S)$ & $321 \pm 15$ & $5 / 5$ & \\
\hline
\end{tabular}


Fig. 1

A

$\begin{array}{cc}6 \mathrm{H} 4 \text { epitope } & { }_{144} \mathrm{WEDRYYRE}_{152} \\ \mathbf{I} \mathbf{I I I I I} \\ \mathrm{SADH}(E) & { }_{397} \mathrm{WVDRYYRD}_{404}\end{array}$

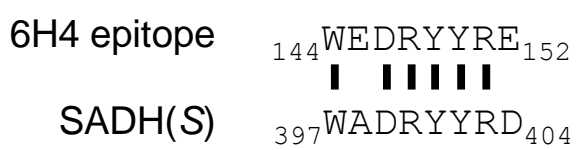

B

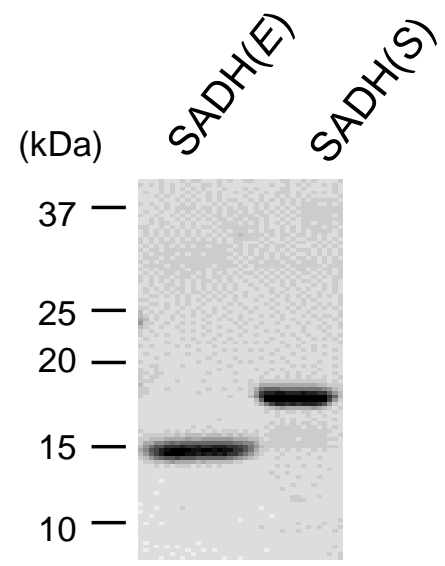

C

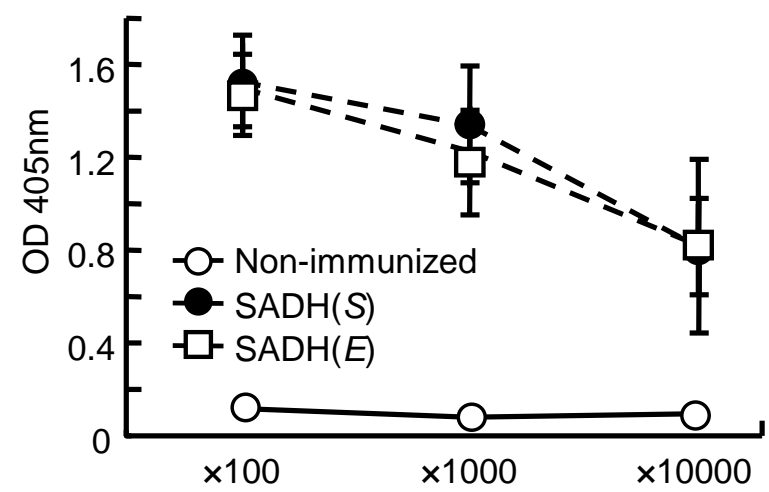

Serum dilution 
Fig. 2

A ELISA antigen: rMoPrP

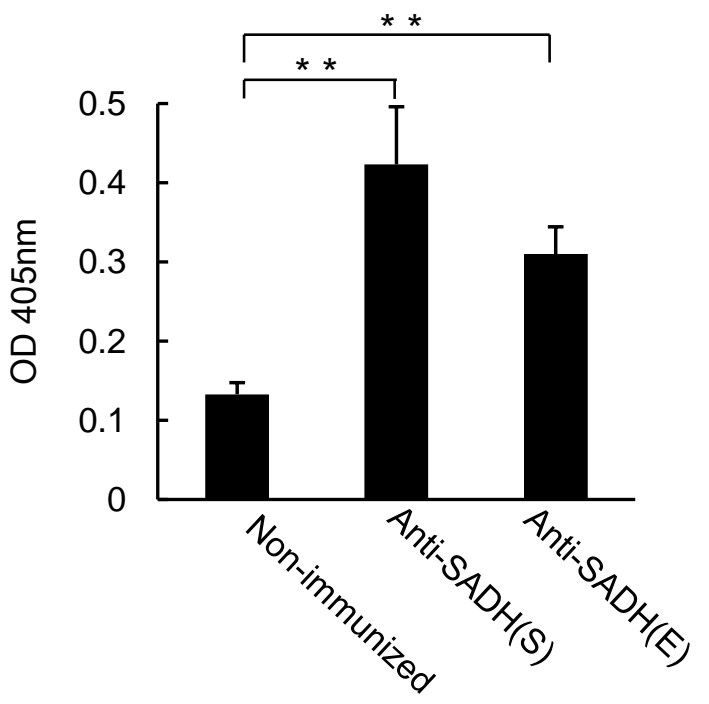

B

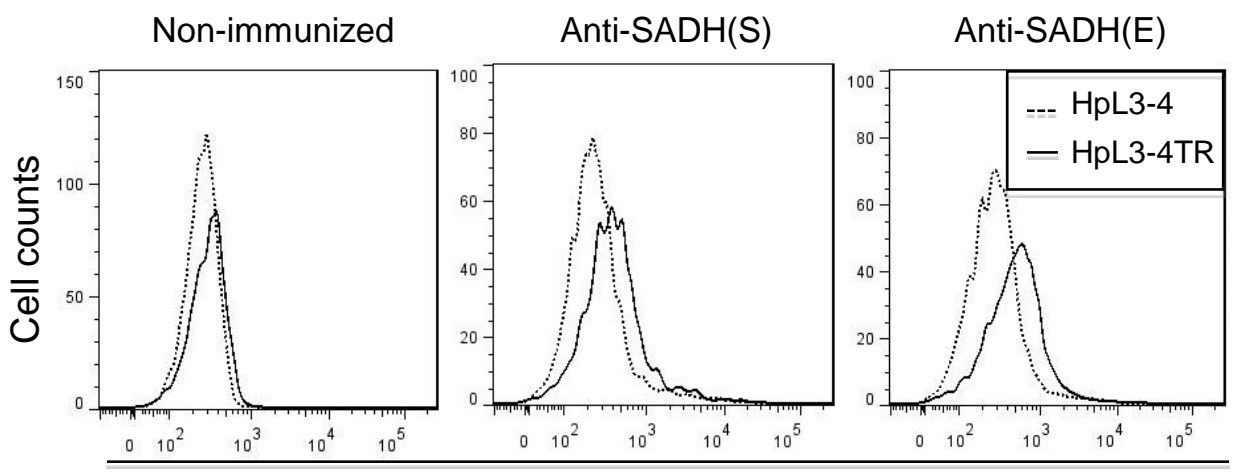

Fluorescence intensity

C ELISA antigen: peptide 131-154

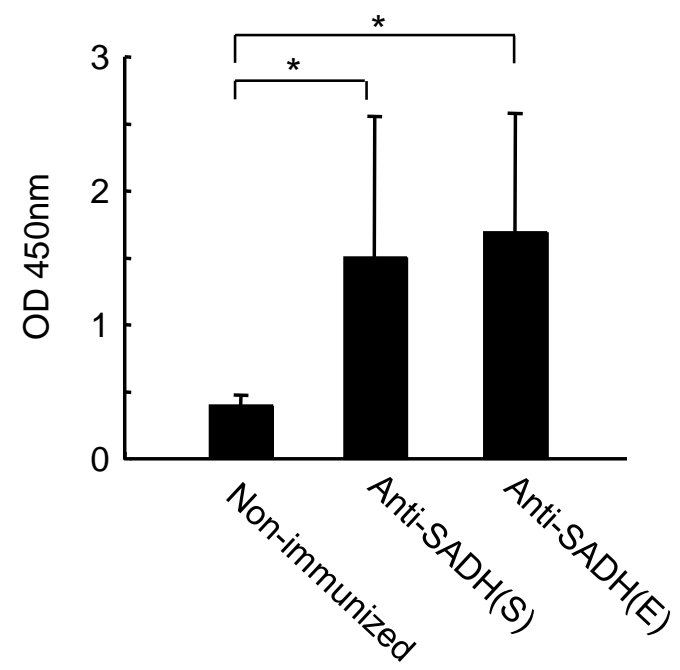


Fig. 3
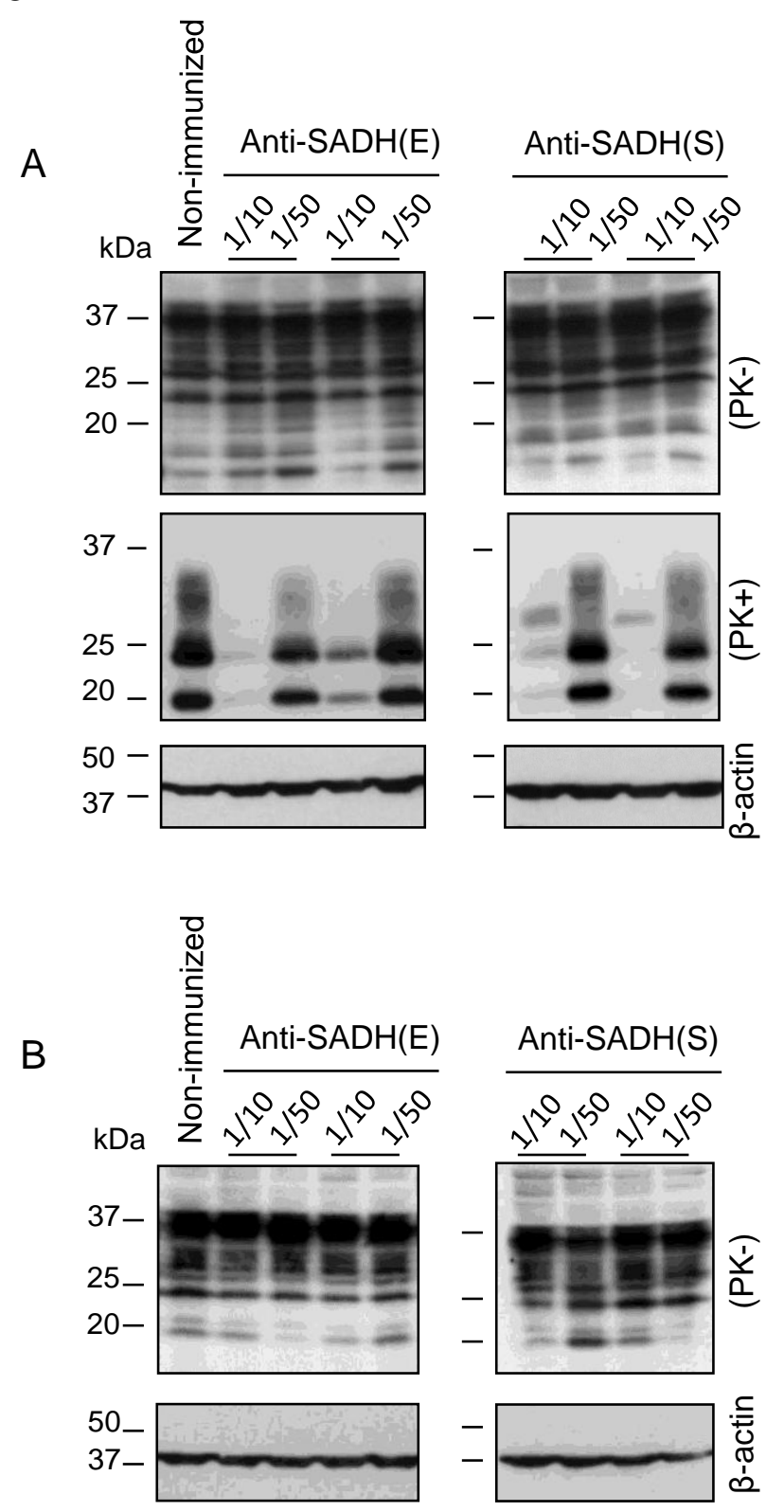

C

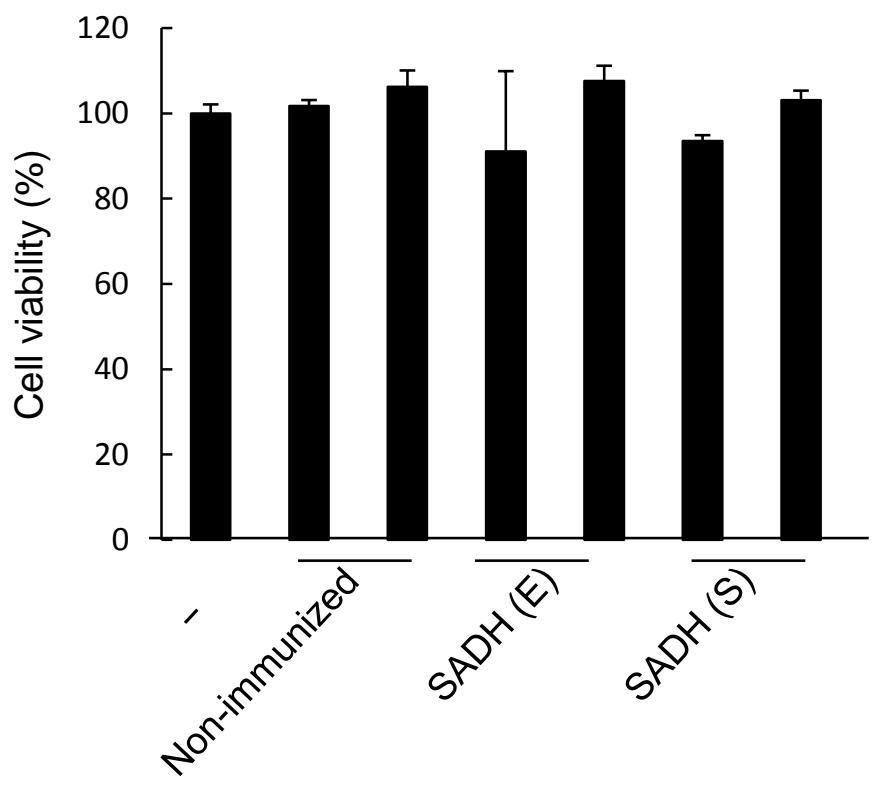


Fig. 4

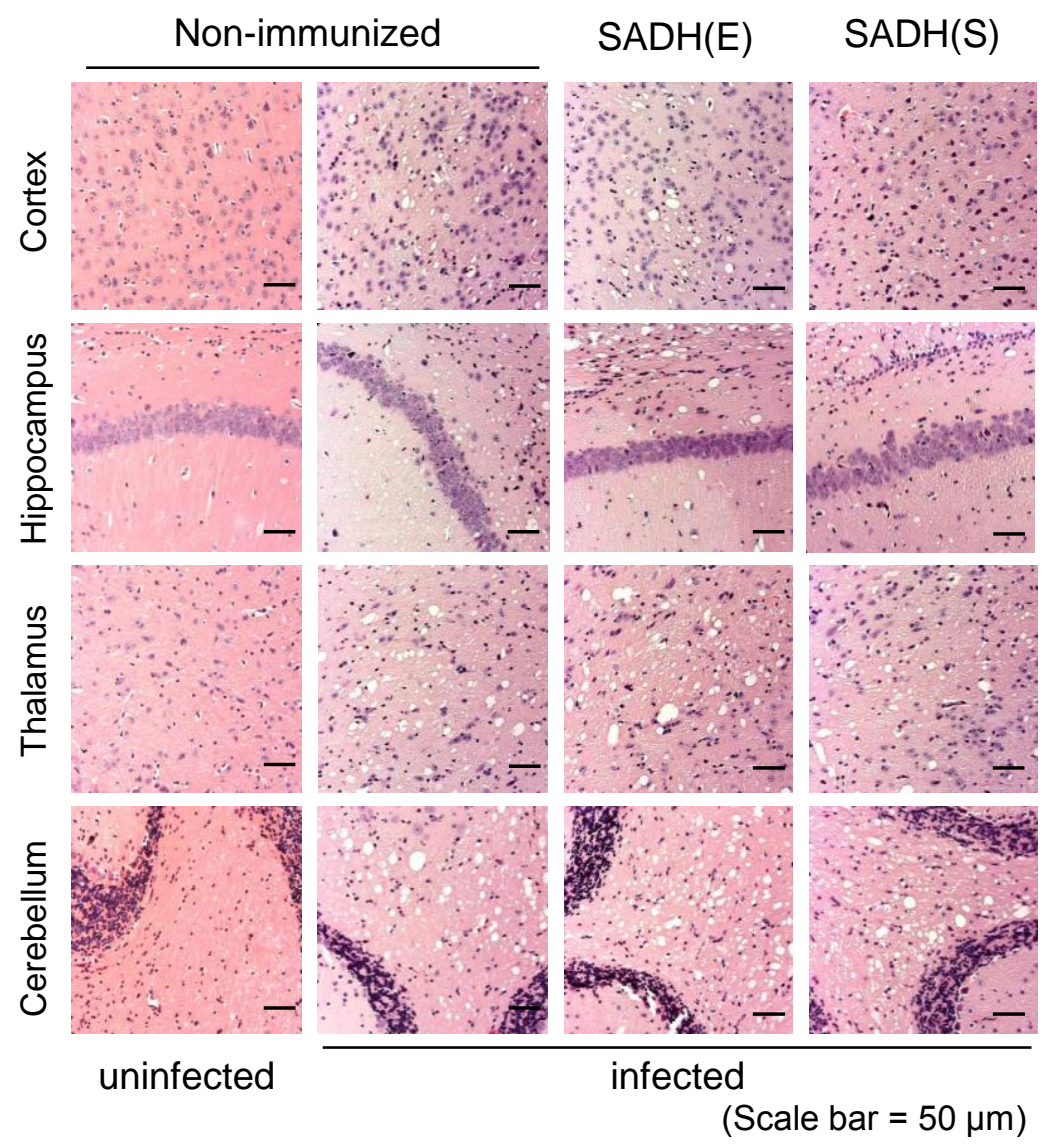

